\title{
Theoretical Analysis on Separation of Complex Flow Velocity in Estuarine Waters
}

\author{
Hao Jialing, He Bingju, and Wang Dong
}

\begin{abstract}
Estuarine velocity distribution is a comprehensive result of oblique pressure, wind stress and wave radiation caused by tidal, runoff and density gradient, which is corresponding to applied forces: tidal flow, runoff flow, density flow, wind-driven flow and wave-driven flow, all the factors contribute to the actual flow. Based on the hydrodynamic feature, the density flow and the wind-driven flow velocity formula in the complex estuarine waters, adopting log-linear model considering the effects of tidal acceleration and deceleration on tidal current profile, the enumerating method combined with the least square is adopted to separate estuarine flow velocity. Directly separating the runoff flow and tidal flow is not available, a second separation should be taken to deal with it because both of them contain the logarithmic items. Firstly, runoff is separated from the period-averaged residual flow, then tidal, wind-driven flows and density flow can be obtained from the instant flow velocity data. The results show that this method is simple in principle, practical in use and can be used to effectively analyze the field data.
\end{abstract}

Index Terms-Velocity separation, estuarine waters, log-linear model, enumeration method, the least square method.

\section{INTRODUCTION}

Estuarine velocity distribution is a comprehensive result of oblique pressure, wind stress and wave radiation caused by tidal, runoff and density gradient, which is corresponding to following factors: tidal flow, runoff, density flow, wind-driven flow and wave-driven flow, all the factors contribute to the actual flow. Among these factors, tidal is the strongest, others are smaller than tidal in order but can also affect the profile of velocity and make the velocity profile deviate from the logarithmic distribution, the deviation degree reflects the strength the factors affecting on the flow.

Many scholars domestic and abroad have done many theoretical researches about estuarine water structure in the condition of multiple hydrodynamic forces. Hansen and Rattary [1] proposed velocity distribution formula which considering the combined effect of runoff, wind-driven flow and density flow, and the formula is still widely used at

Manuscript received January 15, 2015; revised May 5, 2015. The work was supported by "the Fundamental Research Funds for the Central Universities", the title is "Study on vertical structure characteristic of near bottom boundary layer and sediment exchange in the Yangtze estuary" (Grant number: 2009B09914).

Hao Jialing is with the National Engineering Research Center of Water Resources Efficient Utilization and Engineering Safety, Hohai University, Nanjing 210098, China. He is also with College of Harbor, Coastal and Offshore Engineering, Hohai University, Nanjing 210098, China (e-mail: jialingh@hhu.edu.cn).

He Bingju and Wang Dong are with the College of Harbor, Coastal and Offshore Engineering, Hohai University, Nanjing 210098, China (e-mail: 462193777@qq.com; 526544856@qq.com). present. Zhou Ji-Fu [2] decomposed estuarine water into runoff and tidal flow, and built a vertical two-dimensional flow model which was verified by Yangtze river north channel measured data. Kong Jun [3] separated wind-driven flow from the flow in least square method from offshore estuarine actual feature, the calculated data agreed well with the measured data. Ni Zhi-Hui [4] extended this method into a situation which tidal flow, runoff, wind-driven flow and density flow effect together. Ni took Hansen and Rattary's formula which is both parabolic distributed formula in wind-driven current and runoff to fit, the result differed from the actual data greatly although he considered major factors of estuary. And there's a defect in density flow formula that it didn't take salt water mixing into consideration. And tidal flow didn't consider the effect of acceleration and deceleration. All the factors limit the accuracy of velocity separation method.

Flood tide flows to estuary upstream and ebb tide flows to sea in narrow estuary area. Runoff is stable and changes little within a few days. Density flow flows from high density to low density and increases gradually along the channel to the sea. Salinity changes periodically in a tidal cycle.

Wind-driven flow includes two layers usually, under the influence of wind-stress, the top layer velocity's direction are the same as the winds' direction, the bottom layer compensation flow velocity's direction contrasts with the top layer velocity's direction. The direction of wind changes daily and so does wind-driven flow. Wave is in large randomness, and its period is much shorter than tide flow. Wave is not big in most Chinese estuaries, so the method ignores the influence of wave acting on the flow velocity. This paper mainly takes tidal flow, runoff, wind-driven flow and density flow into account.

\section{THEEORETICAL MODEL}

In the assumption of turbulent fluctuation fully developing to the water surface, taking no account of density gradient changes caused by wind, salinity and sediment, runoff can use the logarithmic distribution formula [5]:

$$
u_{c}=\frac{u_{c}^{*}}{\kappa} \ln \frac{\sigma D}{z_{0}}
$$

where $u_{\mathrm{c}}^{*}$ is runoff friction velocity, $\sigma$ is relative water depth, $\kappa=0.4$ is Karman constant.

Previous studies pointed out that due to the acceleration or deceleration action of tide current, the flow structure deviates from traditional logarithmic law in estuary, coast or other near 
shore water [6]-[10]. Tidal flow velocity formula uses the log-linear model,

$$
u_{t}=\frac{u_{t}^{*}}{\kappa}\left(\ln \frac{\sigma D}{z_{0}}+B \sigma D\right)
$$

where $u_{t}^{*}$ is tidal flow friction velocity, $\mathrm{B}$ are the effects of tidal acceleration and deceleration effects, acceleration is positive and deceleration is negative.

Estuarine mixture mainly means mixture of fresh water and salt water, the density difference caused by estuarine mixture is called density flow. Estuary differs a lot with the change of flow cyclical feature, density stratification situation and mixing progress.

Generally speaking, at the time the ratio of runoff and tidal flow is small, tidal effects are strong, every estuarine factor vibrates with the tide, in which contains large amounts of energy. The energy mainly used to conquer riverbed friction velocity or to bring about turbulence. Turbulence eddy conquers density gradient with a large loss of kinetic energy, which makes salt water and fresh water of upper layer interchange intensively.

The density flow formula [11],

$u_{d}=-\frac{g \alpha D^{3}}{N_{z}} \frac{\partial \bar{S}}{\partial x}\left[\begin{array}{c}\frac{1}{30} \sigma^{6}-\frac{1}{10} \sigma^{5}+\frac{1}{3} \sigma^{a}-\frac{13}{30} \sigma^{2}+\frac{1}{6} \sigma \\ +\beta\left(-\frac{1}{30} \sigma^{6}+\frac{1}{10} \sigma^{5}-\frac{1}{6} \sigma^{3}-\frac{29}{240} \sigma^{2}-\frac{1}{24} \sigma\right)\end{array}\right]$

where $\alpha=7.7 \times 10^{-4} \mathrm{psu}^{-1}, D=h+\eta$ is the total depth, $\mathrm{g}$ is the acceleration of gravity, $\mathrm{N}_{\mathrm{Z}}$ is the eddy viscosity, $\bar{S}$ is the section average salinity, $\sigma=(\mathrm{z}+\mathrm{h}) / \mathrm{D}$ is relative distance above the river bed, $\beta=S_{\text {sur }} / S$ is coefficient on behalf of salinity vertical mixing degree.

Wind-driven flow is a very important flow form in ocean, estuary and lakes, many scholars have done flume experiment researches. Baine and Knapp [12] got wind-driven flow average velocity distribution and a conclusion that wind-driven flow velocity distribution and turbulence intensity vary not big with Reynolds number' changing.

Wind-driven flow velocity formula selects double exponential distribution form [11],

$$
u_{w}=A\left[(1-\sigma)^{m}+m \sigma^{m}-1\right]
$$

where $A=-u_{*_{s}} / 4 m \lambda z_{b h}=u_{s} / m-1 \mathrm{~m}, \lambda, z_{b h}$ are double exponential distribution control parameters, $\mathrm{m}$ can be worked out by enumeration method. And $u_{*_{S}}$ is top layer friction velocity, $u_{s}$ is top layer velocity.

\section{SePARATING MethoD}

Directly separating the runoff from tidal flow is not available, a second separation should be taken to deal with it because both of them contain the logarithmic item. Firstly, it is to average velocity data by tidal period, then getting the residual flow velocity and runoff flow velocity; secondly, instantaneous velocity data is subtracted by the runoff velocity to get tidal flow, density flow and wind-driven flow are separated step by step. Take instantaneous velocity separating for example, estuary velocity can be expressed as,

$$
u=u_{t}+u_{d}+u_{w}
$$

where $u_{t}$ is tidal velocity, $u_{d}$ is density velocity, $u_{w}$ is wind-driven velocity, partly substituted by (2), (3), (4):

$$
u=a \varphi_{1}+b \varphi_{2}+c \varphi_{3}+d \varphi_{4}+e \varphi_{5}
$$

where,

$$
\begin{gathered}
\varphi_{1}=\ln \left(\frac{\sigma D}{z_{0}}\right) \\
\varphi_{2}=8 \sigma^{6}-24 \sigma^{5}+80 \sigma^{3}-104 \sigma^{2}+40 \sigma \\
\varphi_{3}=-8 \sigma^{6}+24 \sigma^{5}-40 \sigma^{3}+29 \sigma^{2}-10 \sigma \\
\varphi_{4}=(1-\sigma)^{m}+m \sigma^{m}-1 \\
\varphi_{5}=\sigma \\
\frac{u_{t}^{*}}{k}, b=-\frac{\partial D^{3}}{240 N_{z}} \frac{\partial x}{\partial x}, c=\beta b, d=-\frac{u_{* s}}{4 m \lambda z_{b h}}, \\
e=\frac{D u_{t}^{*}}{\kappa} B .
\end{gathered}
$$

Measured data is substituted in formula (6) for matching to get $a, b, c, d$ and $e$, then to calculate physical parameter. Before matching, roughness length $Z_{0}$ and $\mathrm{m}$ are undetermined, $Z_{0}$ and $\mathrm{m}$ have specific physical meanings and relatively fixed range, they can be fixed by enumeration method [4], [6]-[8], [11], [13]. The method is shown below.

Determining the object function $f=\sum_{i=1}^{n}\left[u\left(\sigma_{i}\right)-u_{i}\right]^{2}$

where $u\left(\sigma_{i}\right)$ can be fixed by formula (6), $\sigma_{i}$ is the height of the $i$ layer, $u_{i}$ is measured value of the $i$ layer, $n$ is the number of layers.

Assuming $z_{0} \in[0.00005,0.05]$, fetch 1000 values and the values differ by 0.00005 . Assume $m$ value of $1 / 3,1 / 4,1 / 5$, $1 / 6,1 / 7,1 / 8,1 / 9$, totally 7000 values. 
For every group of $Z_{0}$ and $\mathrm{m}$, object functions are supposed to use minimum value, so we can know that,

$$
\begin{aligned}
\frac{\partial f}{\partial a}=0 \Rightarrow & \sum_{i=1}^{n}\left[a \phi_{1}\left(\sigma_{i}\right)+b \phi_{2}\left(\sigma_{i}\right)+c \phi_{3}\left(\sigma_{i}\right)\right. \\
& \left.+d \phi_{4}\left(\sigma_{i}\right)+e \phi_{5}\left(\sigma_{i}\right)\right] \phi_{1}\left(\sigma_{i}\right)=\sum_{i=1}^{n} u_{i} \phi_{1}\left(\sigma_{i}\right) \\
\frac{\partial f}{\partial b}=0 \Rightarrow & \sum_{i=1}^{n}\left[a \phi_{1}\left(\sigma_{i}\right)+b \phi_{2}\left(\sigma_{i}\right)+c \phi_{3}\left(\sigma_{i}\right)\right. \\
& \left.+d \phi_{4}\left(\sigma_{i}\right)+e \phi_{5}\left(\sigma_{i}\right)\right] \phi_{2}\left(\sigma_{i}\right)=\sum_{i=1}^{n} u_{i} \phi_{2}\left(\sigma_{i}\right)
\end{aligned}
$$$$
\begin{aligned}
\frac{\partial f}{\partial \mathrm{c}}=0 \Rightarrow & \sum_{i=1}^{n}\left[a \varphi_{1}\left(\sigma_{i}\right)+b \varphi_{2}\left(\sigma_{i}\right)+c \varphi_{3}\left(\sigma_{i}\right)\right. \\
& \left.+d \varphi_{4}\left(\sigma_{i}\right)+e \varphi_{5}\left(\sigma_{i}\right)\right] \varphi_{3}\left(\sigma_{i}\right)=\sum_{i=1}^{n} u_{i} \varphi_{3}\left(\sigma_{i}\right)
\end{aligned}
$$$$
\begin{aligned}
\frac{\partial f}{\partial \mathrm{d}}=0 \Rightarrow & \sum_{i=1}^{n}\left[a \phi_{1}\left(\sigma_{i}\right)+b \phi_{2}\left(\sigma_{i}\right)+c \phi_{3}\left(\sigma_{i}\right)\right. \\
& \left.+d \phi_{4}\left(\sigma_{i}\right)+e \phi_{5}\left(\sigma_{i}\right)\right] \phi_{4}\left(\sigma_{i}\right)=\sum_{i=1}^{n} u_{i} \phi_{4}\left(\sigma_{i}\right)
\end{aligned}
$$$$
\begin{aligned}
\frac{\partial f}{\partial \mathrm{e}}=0 \Rightarrow & \sum_{i=1}^{n}\left[a \phi_{1}\left(\sigma_{i}\right)+b \phi_{2}\left(\sigma_{i}\right)+c \phi_{3}\left(\sigma_{i}\right)\right. \\
& \left.+d \phi_{4}\left(\sigma_{i}\right)+e \phi_{5}\left(\sigma_{i}\right)\right] \phi_{5}\left(\sigma_{i}\right)=\sum_{i=1}^{n} u_{i} \phi_{5}\left(\sigma_{i}\right)
\end{aligned}
$$

By solving the linear equations, $a, b, c, d$ and $e$ can be worked out, and at the same time minimum value $f_{\text {min }}$ will be obtained.

Compare every group of $Z_{0}$ and $\mathrm{m}$ and corresponding $f_{\text {min }}$, choose the smallest $f_{\text {min }}$, and corresponding $a, b, c, d$ and $e$ are the final values.

\section{PHYSICAL PARAMETER EXTRACTION}

After the above steps, the profiles of velocity under various hydrodynamic factors were separated. In addition, it also can extract the physical parameters of the mathematical model of coastal estuaries, which required by several coefficients a, b, c, $\mathrm{d}$ and $\mathrm{e}$.

Friction velocity $u_{*}$ is an important hydrodynamic parameter. The bottom friction is directly proportional to the square of average depth of water flow speed, so friction velocity is used to replace the underwater friction [14].

$$
u_{*}=\kappa a
$$

The trend of deceleration parameter $B$ can be determined by $a$ and $e$

$$
B=\frac{e}{D a}
$$

Salinity mixed coefficient $\beta$ can be determined by $b$ and $c$

$$
\beta=\frac{c}{b}
$$

Surface friction velocity can be determined by $d$

$$
u_{*_{s}}=-4 m \lambda z_{b h} d
$$

where $\lambda$ and $Z_{b h}$ were taken 0.2 and 0.002 in calibration results [11], and $\mathrm{m}$ is determined by the previous enumeration method. Surface shear stress can be determined by $\tau_{w}=\rho u_{* s}^{2}$.

where the index $m$ have been identified and $\lambda$ and $z_{b h}$ were taken 0.2 and 0.002 based on calibration results [11]. Surface shear stress can be obtained according to $\tau_{W}=\rho u_{* S}^{2}$.

There is a relationship between the water $10 \mathrm{~m}$ high wind speed and the surface shear stress

$$
\tau_{w}=\rho_{a} C_{D} W|W|
$$

where, $\rho_{a}$ is the air density, $W$ is the wind speed and $C_{D}$ is the drag coefficient. Pond formula can be used,

$$
C_{D}=10^{-3}(0.61+0.063|W|)(6<W<50)
$$

where, $W$ value exceeds the above range, $C_{D}$ taken corresponds to the minimum $(6 \mathrm{~m} / \mathrm{s})$ or maximum $(50 \mathrm{~m} / \mathrm{s})$ wind speed value.

Calculated Wind from the formula (12) and (13) is consistent with the direction of the velocity. In fact, wind direction can't be same as the direction of the velocity, so to get wind velocity vector it is need to compound the speed of calculated wind and the direction of measured wind.

\section{METHODS VERIFICATION}

Using this method separating vertical velocity distribution data of the wind-flow experiment of Koutitas [15], parameters have been isolated (Table I). Removing factors except the wind-flow velocity is very small impact on the surface velocity, accounting for only $2.3 \%$. It indicates that the method itself causes small error (Seen in Fig. 1).

It can be seen that this method is less interfered by other factors, predicts more accurate on the wind speed and surface velocity.

Wind-driven flow under different wind speeds, surface velocity and wind-flow index are all different. From Fig. 2, separation the two sets of data by Tsuruya (surface wind speed respectively $6.73 \mathrm{~m} / \mathrm{s}$ and $6.9 \mathrm{~m} / \mathrm{s}$ ), was observed that the index will have a great change with the wind speed in the small Reynolds number. Wind speed has a great impact on 
velocity, other power factors impact on velocity proportion of less than $5 \%$.

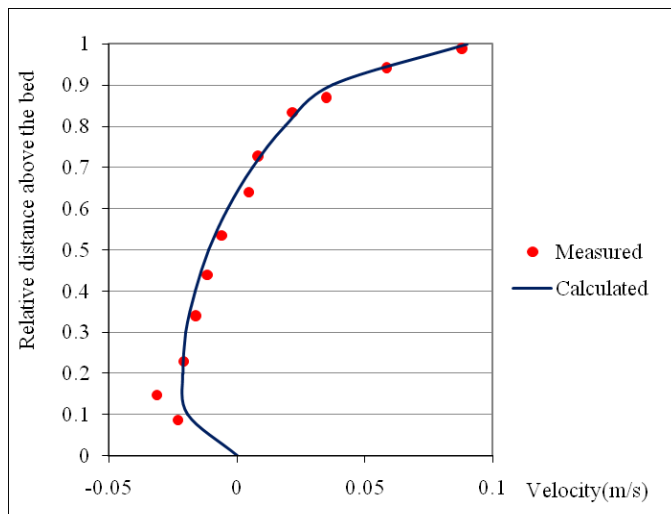

Fig. 1. Comparison of separated and the measured wind-driven velocity profile by Koutitas.

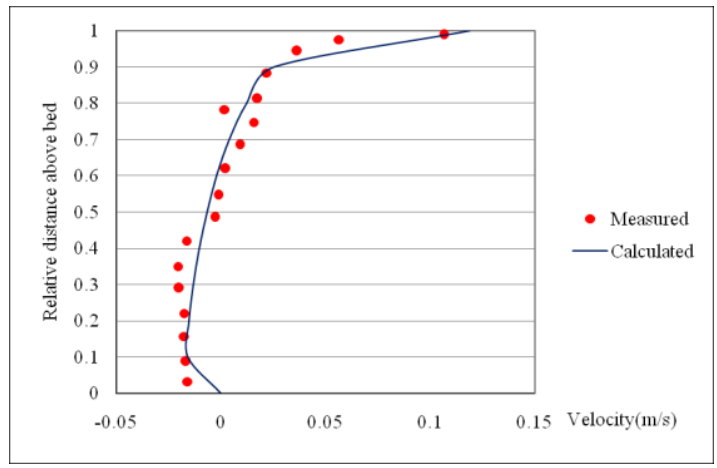

(a) $\operatorname{Re}=16050$

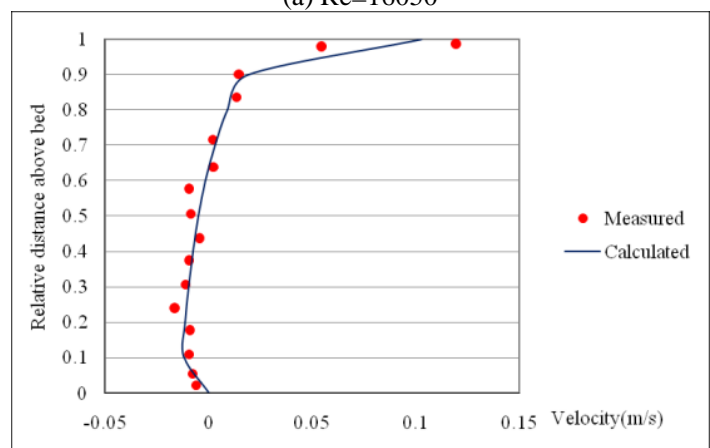

(b) $\operatorname{Re}=18225$

Fig. 2. Comparison of separated and the measured wind-driven velocity profile by Tsuruyua.

TABLE I: SEPARATED WIND-DRIVEN VELOCITY RESULTS (C-CACULATED,

M-MEASURED)

\begin{tabular}{|c|c|l|l|l|}
\hline Experiment & & Koutitas & Tsuruyua(a) & Tsuruyua(b) \\
\hline $\begin{array}{c}\text { Surface velocity } \\
\text { caused by wind (m/s) }\end{array}$ & $\mathrm{C}$ & 0.087 & 0.112 & 0.096 \\
\cline { 2 - 5 } & $\mathrm{M}$ & 0.089 & 0.107 & 0.122 \\
\hline $\begin{array}{c}\text { Surface velocity } \\
\text { caused by other } \\
\text { factors (m/s) }\end{array}$ & $\mathrm{C}$ & 0.002 & 0.001 & 0.005 \\
\cline { 2 - 5 } & $\mathrm{M}$ & 0 & 0 & 0 \\
\hline $\begin{array}{c}\text { Water 10m high wind } \\
\text { speed (m/s) }\end{array}$ & $\mathrm{C}$ & - & 6.78 & 6.96 \\
\cline { 2 - 5 } & $\mathrm{M}$ & - & 6.73 & 6.90 \\
\hline $\begin{array}{c}\text { Roughness height } \\
(\mathrm{m})\end{array}$ & $\mathrm{C}$ & 0.0032 & 0.0008 & 0.0009 \\
\cline { 2 - 5 } & $\mathrm{M}$ & 0.0025 & 0.0002 & 0.0003 \\
\hline $\begin{array}{c}\text { Friction velocity } \\
(\mathrm{m} / \mathrm{s})\end{array}$ & $\mathrm{C}$ & 0.0108 & 0.003 & 0.004 \\
\hline index & $\mathrm{C}$ & $1 / 3$ & $1 / 5$ & $1 / 6$ \\
\hline
\end{tabular}

\section{CONCLUSIONS}

According to the theoretical deduction and analysis, the follow conclusions can be drawn:
1) Using secondary separation method to separate estuarine complex flow velocity, first getting runoff, and then separating the tidal flow, density flow and wind-driven flow.

2) When computing tidal flow, considering the effects of acceleration trend and deceleration effect, the density flows and wind-driven flow formula improve the accuracy of the method. This method can be used to estimate the wind speed, to provide boundary conditions to estuarine and coastal hydrodynamic model and improve the accuracy of the numerical simulation.

3) Improving velocity separation methods. First, using the improved density flow and wind-driven flow distribution formula; Second, using log-linear tidal flow distribution taking into account the effects of acceleration and deceleration.

\section{REFERENCES}

[1] D. V. Hansen and J. M. Rattray, "Gravitational circulation in straits and estuaries," Journal of Marine Research, vol. 23, no. 1, pp. 104-122, 1965.

[2] J. F. Zhou, Q. Q. Liu, and J. C. Li, "Estuary mixing progress research," Science in China, vol. 29, no. 9, pp.835-843, 1999.

[3] J. Kong, Z. Y. Song, and X. H. Chen, "A preliminary study on approach of velocity separation in coastal and estuarine waters," Journal of Hohai University, vol. 29, no. 5, pp. 13-17, 2001.

[4] Z. H. Ni, Z. Y. Song, and L. C. Wu, "An approach to separating the current velocity in estuarine and coastal waters," Journal of Hydrodynamics, vol. 21, no. 4, pp. 512-519, 2009.

[5] P. K. Kundu, I. M. Cohen, and H. H. Hu, Fluid Mechanics, 3rd ed., 2004, Amsterdam; Boston: Elsevier, Academic Press.

[6] J. L. Hao, Z. Y. Song, and Y. X. Yan, "Preliminary study on the tidal velocity profile in the near-bottom layer in the estuary and coast waters," J. of Sediment Research, vol. 1, pp. 25-31, 2006.

[7] J. L. Hao, Z. Y. Song, Y. X. Yan, and H. Q. Li, "Study on the tidal velocity profile in the estuary and coast waters," J. of Sediment Research, vol. 4, pp. 34-41, 2007.

[8] Z. Y. Song, Y. X. Yan, J. L. Hao et al., "The study on log-linear distribution model of tidal velocity in the near-bottom layer in the estuary and coast waters," China Ocean Engineering, vol. 20, no. 4, pp. 573-584, 2006.

[9] R. L. Soulsby and K. R. Dyer, "The form of the near-bed velocity profile in a tidally accelerating flow," J. of Geophysical Research, vol. 86, pp. 8,067-8,074, 1981.

[10] A. Y. Kuo, J. Shen, and J. M. Hamrick, "Effect of acceleration on bottom shear stress in tidal estuaries," J. Waterway, Port, Coastal and Ocean Engineering, vol. 122, no. 2, pp. 75-83, 1996.

[11] Z. Zhang, "Study on complex flow structure analysis and numerical simulation in estuarine waters," Doctor thesis, Hohai university, 2010

[12] W. D. Baines and D. J. Knapp, "Wind driven water current," J. Hydr. Div., vol. 91, no. 2, pp. 205-221, 1965.

[13] J. L. Hao, Y. X. Yan, Z. Y. Song, and C. N. Wang, "The prelimary study on relationship between velocity distribution model and roughness length," in Proc. 25th International Conference on Offshore Mechanics and Arctic Engineering, Hamburg, Germany, June 4-9, 2006. OMAE2006-92417, pp. 1-6.

[14] Z. L. Zou, Coastal Dynamics, China Communications Press, 2009.

[15] C. Koutitas and B. O'Connor, "Modeling three-dimensional wind-induced flow," J. Hydr. Div., vol. 106, pp. 1843-1865, 1980.

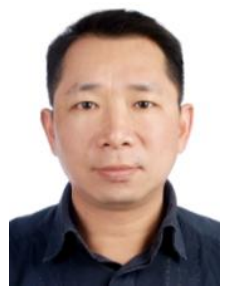

Hao Jialing was born in 1975 at Lincang city, Yunnan province, China. He has got his bachelor of science degree in hydrology and water resources, College of Hydrology and Water Resources, Hohai University, China in 1998. He has got his master of science degree in hydraulics and river dynamics, College of Hydrology and Water Resources, Hohai University, China in 2001. And he has got his doctor of science degree in harbor, coastal and offshore engineering, College of Harbor \& Coastal and Offshore Engineering, Hohai University, China in 2006. From 2007 till now, he has been a lecturer at College of Harbor \& Coastal and Offshore Engineering, Hohai University. His research 
areas include hydraulic, hydrology and water resources, estuarine and coastal hydrodynamic and environmental numerical simulation.

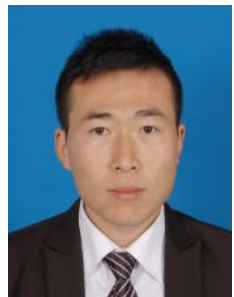

He Bingju was born in 1989 at Lianyungang city, Jiangsu province, China. He has got his bachelor of science degree in hydraulic and hydro-power engineering, College of Hydraulic Engineering, Yangzhou University, China in 2012. He will get his master of science degree in harbor, coastal and offshore engineering, College of Harbor \& Coastal and Offshore Engineering, Hohai University, China in 2015. His research areas include hydraulic, hydrology and water resources, estuarine and coastal hydrodynamic and environment.

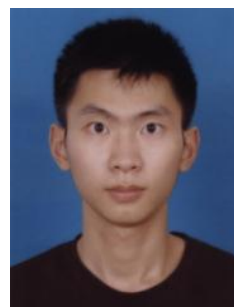

Wang Dong was born in 1992 at Taizhou city, Zhejiang province, China. He has got his bachelor of science degree in underwater science and engineering, College of Environment Engineering, Chang'an University, China in 2013. He will get his master of science was in hydraulic engineering, College of Harbor \& Coastal and Offshore Engineering, Hohai University, China in 2015. His research areas include hydraulic, hydrology and water resources, estuarine and coastal hydrodynamic and environment. 